\title{
Do puzzle pieces and autism puzzle piece logos evoke negative associations?
}

\author{
Morton Ann Gernsbacher ${ }^{1}$, Adam R Raimond ${ }^{1}$, \\ Jennifer L Stevenson ${ }^{2}$, Jilana S Boston ${ }^{1}$ and Bev Harp ${ }^{3}$
}

\begin{abstract}
Puzzle pieces have become ubiquitous symbols for autism. However, puzzle-piece imagery stirs debate between those who support and those who object to its use because they believe puzzle-piece imagery evokes negative associations. Our study empirically investigated whether puzzle pieces evoke negative associations in the general public. Participants' $(N=400)$ implicit negative associations were measured with an Implicit Association Task, which is a speeded categorization task, and participants' explicit associations were measured with an Explicit Association Task, which is a standard task for assessing consumers' explicit associations with brands (and images of those brands). Puzzle pieces, both those used as autism logos and those used more generically, evoked negative implicit associations $(t(399)=-5.357, p<0.001)$ and negative explicit associations $(z=4.693, p<0.001, d=0.491)$. Participants explicitly associated puzzle pieces, even generic puzzle pieces, with incompleteness, imperfection, and oddity. Our results bear public policy implications. If an organization's intention for using puzzle-piece imagery is to evoke negative associations, our results suggest the organization's use of puzzle-piece imagery is apt. However, if the organization's intention is to evoke positive associations, our results suggest that puzzle-piece imagery should probably be avoided.
\end{abstract}

\section{Keywords}

free associations, IAT, Implicit Association Test, puzzle

Puzzle pieces have become pervasive symbols for autism (McGuire, 2012; McGuire and Michalko, 2011; Sarrett, 2011; Smukler, 2005). Puzzle pieces that represent autism appear on numerous products. From t-shirts to designer jewelry, car magnets to credit cards, and beverage holders to smartphone cases, "the puzzle piece as a symbol for autism ... is ubiquitous" (Grinker and Mandell, 2015: 643).

Numerous autism organizations use puzzle pieces in their logos. For example, the US organization Autism Speaks has officially trademarked a blue puzzle piece as its logo. The Autism Society of America has common-law trademarked a ribbon comprising puzzle pieces, and puzzle pieces feature prominently in the logos of many of the Autism Society of America's state chapters (Stevenson et al., 2011).

The depiction of autism as a puzzle piece has permeated scientific vernacular. Research institutions have titled their press releases "Finding the Missing Puzzle Piece of Autism" (O'Connor, 2009) and "Missing Piece Surfaces in the Puzzle of Autism" (CNRS, 2015). Researchers have titled their journal articles "The Puzzling Life of Autistic Toddlers" (Van Rijn and Stappers, 2008), "Solving the Autism Puzzle a Few Pieces at a Time" (Schaaf and Zoghbi, 2011), "The Neurobiology of Autism: New Pieces of the Puzzle" (Acosta and Pearl, 2003), and "Another Piece of the Autism Puzzle" (State, 2010). The International Society for Autism Research has used puzzle imagery on the cover of its annual International Meeting for Autism Research (IMFAR) program. The conception of autism as a puzzle piece is pervasive.

\section{The debate over puzzle piece imagery for autism}

Common lore traces the use of puzzle pieces to represent autism to the United Kingdom. In 1963, the logo of a weeping child superimposed on a puzzle piece was created by a (non-autistic) parent-member of the National Autistic Society. Another (non-autistic) parent-member later related

\footnotetext{
1 University of Wisconsin-Madison, USA

2Ursinus College, USA

3University of Kentucky, USA
}

\section{Corresponding author:}

Morton Ann Gernsbacher, Department of Psychology, University of Wisconsin-Madison, Madison, WI 53706, USA.

Email: MAGernsb@wisc.edu 
that "the puzzle piece is so effective because it tells us something about autism: Our children are handicapped by a puzzling condition; this isolates them from normal human contact and therefore they do not "fit in" (National Autistic Society, 2007).

In current day, the US state of Pennsylvania's Bureau of Autism Services claims that the "puzzle piece [remains] the international symbol for autism" because the puzzle piece conveys "the mystery still surrounding this condition" (Healy, 2008: 141; emphasis ours). The US state of Alaska's Special Education Service Agency claims that puzzle pieces continue to represent autism because of the "many years [that] parents and professionals alike" have been "baffled by this disorder" (Crawford, 2004: 2).

Images of puzzle pieces representing autism flourish on the Internet and in other visual media. Surfing, scouting, running, wrestling, making music, and many activities in which autistic children engage have been represented by puzzle pieces. Sometimes autistic children themselves are caricatured as puzzle pieces (e.g. with the puzzle pieces' top tab representing the children's heads and the puzzle pieces' side tabs representing the children's arms). Other images depict autistic children with a puzzle piece missing from their brain (as on IMFAR program covers). Such imagery is recapitulated by typically developing children's conception of autistic children. When asked why some children have neurodevelopmental disabilities, such as autism, typically developing 9- to 12-year old children report "there is a puzzle piece missing in their brain" (Nowicki et al., 2014: 77).

Numerous autistic persons have objected to the use of puzzle pieces to represent autism and autistic people. For example, Yergeau writes in the journal College English:

Puzzle pieces ... symbolize so much of what is wrong with popular autism discourse-representing autistic people as puzzling, mysterious, less-than-human entities who are "short a few cognitive pieces," who are utterly self-contained, disconnected, and [who] need to "fit in" (Heilker and Yergeau, 2011: 494)

Brook (2016) begins a letter to the editor of the journal Autism, which uses puzzle-piece imagery both on its cover and in its masthead, by writing, "I will not attempt to detail why the puzzle piece as a symbol for autism is offensive; it is easy to search online and find many and varied reasons from different authors" (p. 251) (see, for example, Endow, 2014; Hillary, 2013; Ised, 2012; Nakhla-Thometz, 2013; Regan, 2015; Tucker, 2008; Wyatt, 2008).

Thus, while many autism organizations continue to use puzzle-piece imagery, many autistic people object. Ergo, puzzle-piece imagery stirs debate (Edmunds, 2013; GoinKochel, 2016; Grinker and Mandell, 2015; Muzikar, 2015). To our knowledge, however, no research has empirically examined whether puzzle-piece images evoke negative associations in the general public. That was the purpose of our study. We measured participants' implicit and explicit associations to puzzle pieces, both those used as autism logos and those used more generically.

Members of the general public completed an Implicit Association Test (Greenwald et al., 1998), which is a speeded categorization task often used to measure implicit attitudes (including attitudes toward images of brands, Maison et al., 2004). Participants categorized images of puzzle pieces and matching images of non-puzzle piece shapes. During test trials, the images of puzzle pieces or shapes were paired with either negative or positive concepts. Shorter latencies to categorize puzzle pieces versus shapes when they were paired with negative versus positive concepts indicated negative implicit biases. Participants also completed an Explicit Association Task, which is a standard task for assessing consumers' explicit associations with brands (using images of those brands; Koll et al., 2010; Krishnan, 1996; Spears et al., 2006).

\section{Method \\ Participants}

We pre-specified our sample size according to Nosek's (2005) extensive analysis of Implicit Association Tasks. In each of Nosek's analyses, an average of 200 participants were assigned to each material set. Because our study had two material sets, our sample size was 400 adults who were recruited through Amazon Mechanical Turk. Data from 30 other participants were excluded: 19 participants responded too rapidly (more than $10 \%$ of their response times were faster than $300 \mathrm{~ms}$, which requires removal from the data set according to Greenwald et al., 2003); 4 participants had complications from either their Internet connection or their own computers; and 7 participants failed to provide a Mechanical Turk authorization code.

Of the 400 participants, $53.00 \%$ identified as men; $46.00 \%$ identified as women; $0.75 \%$ identified outside the gender binary; and $0.25 \%$ did not wish to disclose their gender. The participants' average age was 33.76 years (standard deviation $(S D)=10.37), 97.99 \%$ reported that English was their native language, and $98.80 \%$ reported living in the United States for most of the past five years. Fewer than $1 \%(0.50 \%)$ identified as having an autism spectrum diagnosis; $3.00 \%$ identified as working with autistic persons; $12.00 \%$ as being a friend of an autistic person; and $15.00 \%$ as having an autistic relative.

Participants were kept naive about the research hypothesis. The experiment was titled "Concepts and Images," and, when recruited, participants were told that "In this study, you will be asked to classify written concepts into two categories and classify visual images into two categories." Participants were compensated US $\$ 1$ for their participation in the 10-minute study. 


\section{Stimuli}

For the Implicit Association Task, the image stimuli comprised 10 images of generic PUZZLE pieces with 10 matching geometric SHAPEs and 10 images of autism PUZZLE piece logos with 10 matching geometric SHAPE logos. The generic puzzle piece images were royalty-free clip art, and the autism puzzle piece logos were taken from autism organizations' logos and products. The geometric shapes, which were rectangles, ovals, stars, triangles, rounded rectangles, and the like, matched their respective puzzle pieces in color, texture, border, shading, and size. All stimuli are available at the Open Science Framework, https://osf.io/mv2zt/.

The concept stimuli comprised 10 nouns representing NEGATIVE concepts (e.g. grief, agony, cancer) and 10 nouns representing POSITIVE concepts (e.g. cheer, paradise, laughter), which had been used in previous studies (e.g. Greenwald et al., 1998). The 10 NEGATIVE and 10 POSITIVE concept words did not differ in length, as measured in letters $(M=6.500, S D=1.434$ and $M=6.100, S D=1.197 ; t(18)=0.677, p=0.507, d=0.303$ ) or syllables $(M=2.000, S D=0.817$ and $M=2.100$, $S D=0.738 ; t(18)=-0.287, p=0.777, d=-0.129)$. One NEGATIVE and one POSITIVE concept, as well as one generic PUZZLE piece and its matching generic SHAPE and one autism PUZZLE piece logo and its matching autism SHAPE logo, were used to illustrate the task and allow participants to practice during the trials that preceded the test blocks.

\section{Material sets}

Four material sets were constructed, Generic-Material-Set A (illustrated in Figure 1), Logo-Material-Set A (illustrated in Figure 2), Generic-Material-Set B, and Logo-MaterialSet $\mathrm{B}$, by counterbalancing two between-subjects variables: (1) whether PUZZLE pieces were associated with NEGATIVE concepts during the first test block and POSITIVE concepts during the last test block (GenericMaterial-Set A and Logo-Material-Set A) or PUZZLE pieces were associated with NEGATIVE concepts during the last test block and POSITIVE concepts during the first test block (Generic-Material-Set B and Logo-Material-Set B) and (2) whether the images were Generic PUZZLE pieces and SHAPEs (Generic-Material-Set A and GenericMaterial-Set B) or Autism Logos PUZZLE pieces and SHAPEs (Logo-Material-Set A and Logo-Material-Set B).

The order of image and concept stimuli was identical across the four material sets and was pseudo-randomly arranged so that each image or concept occurred only once within each of the two test blocks, and no more than three trials containing concepts or images occurred consecutively. One hundred participants were randomly assigned to each material set and did not differ in age $(F(3,394)=1.241$,

\begin{tabular}{|c|c|c|}
\hline $\begin{array}{l}\text { Block 1: } \\
\text { Practice } \\
18 \text { Trials }\end{array}$ & SHAPE & SHAPE \\
\hline $\begin{array}{l}\text { Block 2: } \\
\text { Practice } \\
18 \text { Trials }\end{array}$ & $\begin{array}{l}\text { NOSITIVE } \\
\text { grief }\end{array}$ & $\begin{array}{c}\text { Positive } \\
\text { cheer }\end{array}$ \\
\hline $\begin{array}{l}\text { Block 3: } \\
\text { Practice } \\
4 \text { Trials }\end{array}$ & $\left.\right|_{\text {POSITIVE }} ^{\text {SHAPE }} \boldsymbol{S}^{\text {PUZZZLEE }}$ & \begin{tabular}{|lr} 
SHAPE & PUZZLE \\
POSITIVE & NEGATIVE \\
\end{tabular} \\
\hline $\begin{array}{l}\text { Block 4: } \\
\text { FIRST TEST } \\
72 \text { Trials }\end{array}$ & \begin{tabular}{|l} 
SHAPE \\
POSITIVE \\
grief
\end{tabular} & $\begin{array}{l}\text { SHAPE } \\
\text { POSITIVE } \\
\text { cheer }\end{array}$ \\
\hline $\begin{array}{l}\text { Block 5: } \\
\text { Practice } \\
18 \text { Trials }\end{array}$ & SHAPE & PUZZLEE \\
\hline $\begin{array}{l}\text { Block 6: } \\
\text { Practice } \\
4 \text { Trials }\end{array}$ & ${ }^{\text {PUZZZLE }}$ & $\begin{array}{l}\text { PUZZLE } \\
\text { POSITIVE }\end{array}$ \\
\hline $\begin{array}{l}\text { Block 7: } \\
\text { LAST TEST } \\
72 \text { Trials }\end{array}$ & 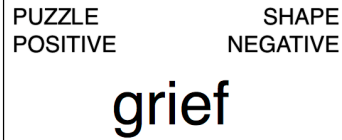 & \begin{tabular}{|l} 
PUZZLE \\
POSITIVE \\
cheer
\end{tabular} \\
\hline
\end{tabular}

Figure 1. Example Implicit Association trials for GenericMaterial-Set A.

$\left.p=0.294, \eta^{2} \mathrm{p}=0.009\right)$, gender $\left(\chi^{2}(3)=6.028, p=0.110\right.$, Cramer's $V=0.123$ ), having an autism spectrum diagnosis $\left(\chi^{2}(3)=2.022, p=0.568, V=0.073\right)$, being friends with an autistic person $\left(\chi^{2}(3)=1.170, p=0.760, V=0.051\right)$, working with autistic persons $\left(\chi^{2}(3)=2.103, p=0.551, V=0.074\right)$, or having an autistic relative $\left(\chi^{2}(3)=5.018, p=0.171\right.$, $V=0.051)$.

\section{Procedure}

Implicit Association Task. The Implicit Association Task comprised 206 trials, divided into seven blocks, as illustrated in Figures 1 and 2. During Block 1, participants practiced categorizing images that were either PUZZLE pieces or SHAPEs. For participants assigned to GenericMaterial-Set A (Figure 1) or Logo-Material-Set A (Figure 2), the category label SHAPE appeared on the left and PUZZLE appeared on the right side of their computer screen; therefore, participants pressed the ' $E$ ' key (on the left side of their computer keyboards) if the image was a SHAPE or the 'I' key (on the right side of their keyboards) if the image was a PUZZLE. For participants assigned to Generic-Material-Set B or Logo-Material-Set B, the category label PUZZLE appeared on the left and SHAPE appeared on the right; therefore, participants pressed ' $E$ ' if the image was a PUZZLE or 'I' if the image was a SHAPE. 


\begin{tabular}{|c|c|c|c|c|}
\hline $\begin{array}{l}\text { Block 1: } \\
\text { Practice } \\
18 \text { Trials }\end{array}$ & SHAPE & PUZZLE & SHAPE & PUZZLE \\
\hline $\begin{array}{l}\text { Block 2: } \\
\text { Practice } \\
18 \text { Trials }\end{array}$ & POSITIVE & $\begin{array}{l}\text { NEGATIVE } \\
\text { f }\end{array}$ & $\begin{array}{r}\text { POSITIVE } \\
\text { C }\end{array}$ & $\begin{array}{l}\text { NEGATIVE } \\
\partial r\end{array}$ \\
\hline $\begin{array}{c}\text { Block 3: } \\
\text { Practice } \\
4 \text { Trials }\end{array}$ & \begin{tabular}{|l|} 
SHAPE \\
POSITIVE
\end{tabular} & $\begin{array}{r}\text { PUZZLE } \\
\text { NEGATIVE }\end{array}$ & \begin{tabular}{|l} 
SHAPE \\
POSITIVE
\end{tabular} & $\begin{array}{r}\text { PUZZLE } \\
\text { NEGATIVE }\end{array}$ \\
\hline $\begin{array}{l}\text { Block 4: } \\
\text { FIRST TEST } \\
72 \text { Trials }\end{array}$ & \begin{tabular}{|l} 
SHAPE \\
POSITIVE
\end{tabular} & $\begin{array}{l}\text { PUZZLE } \\
\text { NEGATIVE } \\
\end{array}$ & $\begin{array}{r}\text { SHAPE } \\
\text { POSITIVE } \\
\text { C }\end{array}$ & $\begin{array}{r}\text { PUZZLE } \\
\text { NEGATIVE } \\
\text { r }\end{array}$ \\
\hline $\begin{array}{l}\text { Block 5: } \\
\text { Practice } \\
18 \text { Trials }\end{array}$ & PUZZLE & SHAPE & PUZZLE & SHAPE \\
\hline $\begin{array}{l}\text { Block 6: } \\
\text { Practice } \\
4 \text { Trials }\end{array}$ & \begin{tabular}{|l} 
PUZZLE \\
POSITIVE
\end{tabular} & $\begin{array}{r}\text { SHAPE } \\
\text { NEGATIVE }\end{array}$ & \begin{tabular}{|l|} 
PUZZLE \\
POSITIVE
\end{tabular} & $\begin{array}{r}\text { SHAPE } \\
\text { NEGATIVE }\end{array}$ \\
\hline $\begin{array}{l}\text { Block 7: } \\
\text { LAST TEST } \\
72 \text { Trials }\end{array}$ & $\begin{array}{l}\text { PUZZLE } \\
\text { POSITIVE }\end{array}$ & $\begin{array}{r}\text { SHAPE } \\
\text { NEGATIVE }\end{array}$ & $\begin{array}{l}\text { PUZZLE } \\
\text { POSITIVE }\end{array}$ & $\begin{array}{r}\text { SHAPE } \\
\text { NEGATIVE } \\
\end{array}$ \\
\hline
\end{tabular}

Figure 2. Example Implicit Association trials for LogoMaterial-Set A.

During Block 2, participants practiced categorizing lexical concepts that had POSITIVE (e.g. cheer ) or NEGATIVE connotations (e.g. grief ). For all participants, the category label POSITIVE appeared on the left and NEGATIVE appeared on the right; therefore, participants pressed ' $E$ ' if the concept was POSITIVE or 'I' if the concept was NEGATIVE. During Block 3, participants practiced categorizing images (PUZZLE or SHAPE) while also categorizing concepts (POSITIVE or NEGATIVE). During Block 4, participants continued to categorize images (PUZZLE or SHAPE) while also categorizing concepts (POSITIVE or NEGATIVE), and the 72 trials in Block 4 served as the first set of test trials.

During Block 5, participants again practiced categorizing only images because the response keys (and the location of the image category labels) were reversed. For participants assigned to Generic-Material-Set A (Figure 1) or Logo-Material-Set A (Figure 2), the category label PUZZLE appeared on the left and SHAPE appeared on the right; therefore, participants pressed ' $E$ ' if the image was a PUZZLE or 'I' if the image was a SHAPE. The opposite was true for participants assigned to GenericMaterial-Set B or Logo-Material-Set B. During Block 6, participants practiced categorizing images while also categorizing concepts, with the response key mapping established during Block 5. During Block 7, participants continued to categorize images while also categorizing concepts, and the 72 trials in Block 7 served as the last set of test trials.

Participants were encouraged to rest their index fingers on the 'E' and 'I' keys for the duration of the task. They were encouraged to make their categorizations as rapidly as possible, without making too many errors. If participants made an error, a red $\mathrm{X}$ appeared on the screen, and they were required to press the correct key to continue.

Explicit Association Task. After completing the Implicit Association Task, participants completed a short questionnaire, which also assayed demographic information (e.g. age, gender). Two items in the short questionnaire provided the Explicit Association Task: "When I see a shape, the first few thoughts that come to my mind are ___ " and "When I see a puzzle piece, the first few thoughts that come to my mind are The participants were given five lines for typing five free associations for each of the two statements.

\section{Data analysis}

The Implicit Association Task data were analyzed via traditional analyses of variance (ANOVAs) and planned comparison $t$-tests on participants' mean correct latencies and error rates for categorizing images in each of the two test blocks. The Implicit Association Task data were also analyzed via the Implicit Association Test scoring algorithm (Greenwald et al., 2003). For both the ANOVAs and the Implicit Association Test scoring algorithm, categorization latencies longer than 10,000 ms were removed. The Explicit Association data were analyzed with chi-square and $z$-tests. For all analyses, an alpha level of 0.001 was adopted to protect against type I error.

Mean correct latencies and error rates. The primary dependent variables comprised participants' mean correct latencies and error rates to categorize images in the two test blocks (i.e. Block 4 and Block 7 in Figures 1 and 2). One block of test trials provided participants' mean correct latencies and error rates for categorizing PUZZLE pieces paired with NEGATIVE concepts and SHAPEs paired with POSITIVE concepts (Block 4 for Generic-MaterialSet A and Logo-Material-Set A; Block 7 for GenericMaterial-Set B and Logo-Material-Set B). The other block of test trials provided participants' mean correct latencies and error rates for categorizing PUZZLE pieces paired with POSITIVE concepts and shapes paired with NEGATIVE concepts (Block 4 for Generic-Material-Set B and Logo-Material-Set B; Block 7 Generic-Material-Set A and Logo-Material-Set A).

Implicit Association Scores. The third dependent variable comprised participants' Implicit Association Scores, computed 
via the algorithm specified by Greenwald et al. (2003). A mean correct latency was computed for each participant for each of the two test blocks, averaging across all trials in each test block. For each participant, a pooled SD (of each participant's correct latencies) was computed across the two test blocks. Next, each participant's error latencies were replaced with that participant's mean correct latency (for that test block) plus $600 \mathrm{~ms}$. Then, a difference score was computed for each participant, subtracting one test block from the other test block so that a negative Implicit Association Score indicated negative implicit associations to puzzle pieces. Finally, each participant's difference score was divided by that participant's pooled SD, producing an Implicit Association Score.

Explicit Associations. The fourth dependent variable comprised the participants' Explicit Associations, which were coded independently by two of the authors (JLS and JSB), naive to which material set the participants had been randomly assigned (the coders were unable to remain naive to the prompt to which participants had responded because of the nature of participants' responses, for example, responding "where does it fit?" or "jigsaw" in response to "When I see a puzzle piece, the first few thoughts that come to my mind are __ " and responding "oval" and "square" in response to "When I see a shape, the first few thoughts that come to my mind are ").

Participants' Explicit Associations were classified into four mutually exclusive categories: Negative Associations (e.g. "problem," "bad," "ugly," or "sad"), Positive Associations (e.g. "fun," "happy," "good," or "pleasant"), Neutral Associations (e.g. "where does it fit?", "jigsaw," "oval," or "square"), and No Associations (i.e. the participant left the line blank). The coders agreed on $96.13 \%$ of the calssifications, and disagreements were resolved by consensus.

\section{Results}

\section{Mean correct latencies and error rates}

Participants' mean correct latencies and error rates are illustrated in Figure 3. As shown in the left panel, the shortest latencies were observed when participants responded with the key that paired PUZZLE pieces with NEGATIVE concepts ( $M=846 \mathrm{~ms}, S D=194 \mathrm{~ms})$. These PUZZLE-NEGATIVE pairings were categorized with significantly shorter latencies than SHAPE-NEGATIVE pairings $(M=916 \mathrm{~ms}, S D=214 \mathrm{~ms}, t(399)=-7.661, p<0.001),{ }^{1}$ PUZZLE-POSITIVE pairings ( $M=889 \mathrm{~ms}, S D=203 \mathrm{~ms}$, $t(399)=-4.761, p<0.001)$, and SHAPE-POSITIVE pairings $(M=885 \mathrm{~ms}, S D=204 \mathrm{~ms}, t(399)=-6.749, p<0.001)$, resulting in a significant interaction between image category (PUZZLE vs SHAPE) and concept connotation (NEGATIVE vs POSITIVE, $\left.F(1,398)=19.16, p<0.001, \eta^{2} \mathrm{p}=0.046\right)$. As shown in the right panel of Figure 3, PUZZLE-NEGATIVE pairings were also categorized at a significantly

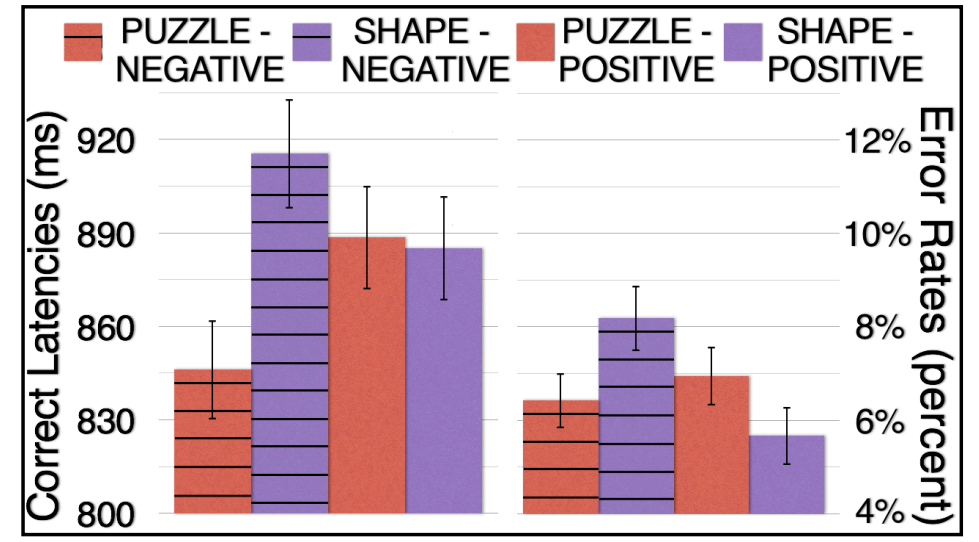

Figure 3. Participants' mean correct latencies (left side of figure) and error rates (right side of figure) for categorizing images as PUZZLE pieces or SHAPEs when paired with NEGATIVE or POSITIVE concepts. Error bars are $99.9 \%$ confidence intervals (Cls) of the mean.

lower error rate $(M=6.431 \%, S D=7.218 \%)$ than SHAPENEGATIVE pairings $(M=8.188 \%, S D=8.538 \%$, $t(399)=-4.207, p<0.001)$, although error rates to PUZZLENEGATIVE pairings did not differ significantly from error rates to PUZZLE-POSITIVE pairings $(M=6.945 \%$, $S D=7.705 \%, t(399)=1.318, p=0.188)$ or SHAPE-POSITIVE pairings $(M=5.667 \%, S D=7.632 \%, t(399)=2.550, p=0.011)$. The significantly lower error rates for PUZZLE-NEGATIVE pairings than SHAPE-NEGATIVE pairings resulted in a significant interaction between image category (PUZZLE vs SHAPE) and concept connotation (NEGATIVE vs POSITIVE; $F(1,398)=16.95$, $\left.p<0.001, \eta^{2} \mathrm{p}=0.041\right)$.

Neither participants' mean correct latencies nor their error rates led to a significant three-way interaction among image type (Generic Images vs Autism Logos), image category (PUZZLE vs SHAPE), and concept connotation (NEGATIVE vs POSITIVE; $F(1,398)=3.511, p=0.062$, $\eta^{2} \mathrm{p}=0.009$ for mean correct latencies; $F(1,398)=2.132$, $p=0.145, \eta^{2} \mathrm{p}=0.005$ for error rates). The lack of a significant three-way interaction suggests that participants' negative implicit associations to puzzle pieces were unaffected by whether the puzzle pieces were generic images or autism logos.

Indeed, Generic Image PUZZLE-NEGATIVE pairings ( $M=796 \mathrm{~ms}, S D=142 \mathrm{~ms}$ ) were categorized significantly faster than Generic Image SHAPE-NEGATIVE pairings $(M=885 \mathrm{~ms}, S D=206 \mathrm{~ms}, t(199)=-7.041, p<0.001)$, Generic Image PUZZLE-POSITIVE pairings $(M=851 \mathrm{~ms}$, $S D=184 \mathrm{~ms}, t(199)=-4.708, p<0.001)$, and Generic Image SHAPE-POSITIVE pairings $(M=836 \mathrm{~ms}$, $S D=168 \mathrm{~ms}, t(199)=-5.374, p<0.001)$. Similarly, Autism Logo PUZZLE-NEGATIVE pairings $(M=896 \mathrm{~ms}$, $S D=224 \mathrm{~ms}$ ) were categorized significantly faster than Autism Logo SHAPE-NEGATIVE pairings $(M=946 \mathrm{~ms}$, $S D=218 \mathrm{~ms}, t(199)=-3.872, p<0.001)$ and Autism Logo SHAPE-POSITIVE pairings $(M=934 \mathrm{~ms}, S D=224 \mathrm{~ms}$, 


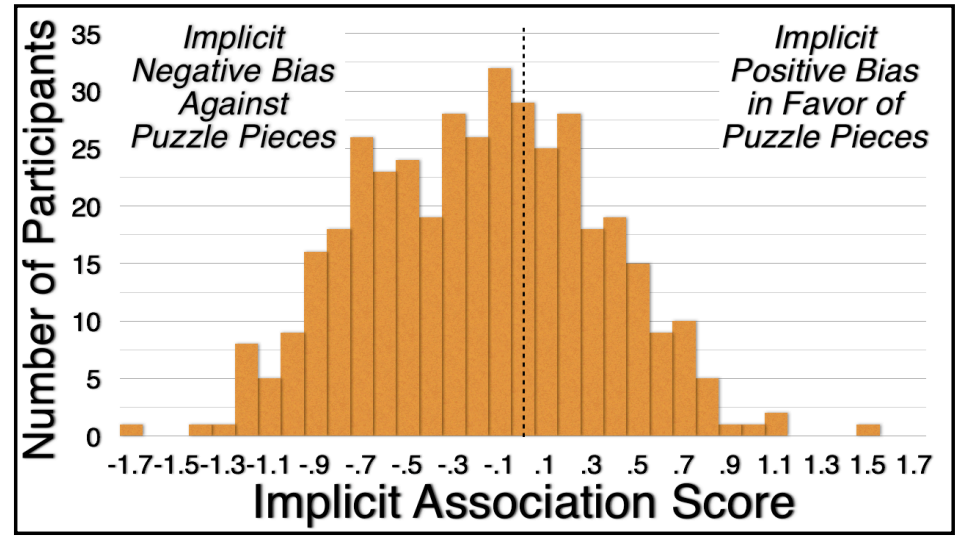

Figure 4. Distribution of participants' Implicit Association Scores. The dashed line at zero indicates zero negative or positive implicit bias.

$t(199)=-4.292, p<0.001)$, although not significantly faster than Autism Logo PUZZLE-POSITIVE pairings $(M=926 \mathrm{~ms}, S D=215 \mathrm{~ms}, t(199)=-2.226, p=0.027)$.

To summarize, participants' mean correct latencies and error rates demonstrated that members of the general population have negative implicit biases against puzzle pieces.

Participants' negative implicit biases against puzzle pieces encompass generic puzzle pieces and autism logo puzzle pieces.

\section{Implicit Association Scores}

Figure 4 presents the distribution of participants' Implicit Association Scores. The dashed line at zero indicates zero negative or positive implicit bias. Participants' mean Implicit Association Score, $-0.137(S D=0.511)$, was significantly more negative than zero $(t(399)=-5.357, p<0.001)$, indicating a significant negative bias against puzzle pieces. The mean Implicit Association Score of participants who categorized Generic Images $(M=-0.199, S D=0.529)$ did not differ significantly from the mean Implicit Association Score of participants who categorized Autism Logos $(M=-0.075$, $\left.S D=0.486 ; F(1,398)=5.887, p=0.016, \eta^{2}=0.015\right)$.

To summarize, participants' Implicit Association Task Scores, like their mean correct latencies and error rates, indicate that members of the general population have a negative implicit bias against puzzle pieces. Participants' negative implicit bias against puzzle pieces encompasses autism logo puzzle pieces and generic puzzle pieces.

\section{Explicit Associations}

Participants' negative versus positive Explicit Associations to "seeing a puzzle piece" differed significantly from their negative versus positive Explicit Associations to "seeing a shape" $\left(\chi^{2}(1)=22.00, p<0.001, d=0.324\right)$. Participants produced significantly more negative Explicit Associations in response to "seeing a puzzle piece" $(50 \% \pm 6.76 \%, 99.9 \%$ CI) than in response to "seeing a shape" (33\% $\pm 9.44 \%$; $z=4.693, p<0.001, d=0.491)$. Participants also produced significantly fewer positive Explicit Associations in response to "seeing a puzzle piece" $(50 \% \pm 6.76 \%)$ than in response to "seeing a shape" $(67 \% \pm 9.44 \% ; z=-4.693$, $p<0.001, d=0.441)$.

Participants produced significantly more negative Explicit Associations in response to "seeing a puzzle piece" than "seeing a shape" regardless of whether they had performed the Implicit Association Task on Generic Images or Autism Logos $\left(\chi^{2}(1)=0.320, p=0.572, d=0.058\right)$. Similarly, participants produced significantly fewer positive Explicit Associations in response to "seeing a puzzle piece" than "seeing a shape" regardless of whether they had performed the Implicit Association Task on Generic Images or Autism Logos $\left(\chi^{2}(1)=0.368, p=0.544, d=0.056\right)$.

To summarize, participants' Explicit Associations, like their Implicit Associations, demonstrate that members of the general population have negative explicit associations with puzzle pieces.

\section{Discussion}

This study examined the general public's associations to puzzle piece images, both those used as autism logos and those used more generically. Using the Implicit Association Task, this study demonstrated that the general public has a negative implicit bias against puzzle pieces. Participants categorized images of puzzle pieces significantly more rapidly and accurately when the response key was paired with identifying negative connotations. Participants' average Implicit Association Score was also significantly negative. Although of moderate magnitude, participants' mean Implicit Association Score resembles the magnitude reported in studies examining the general population's implicit bias against images of ethnic minorities (Devos and Ma, 2008; Foroni and Bel-Bahar, 2010; Nosek, 2005).

Using an Explicit Association Task, this study also demonstrated that the general public has negative explicit associations to puzzle pieces. Half the participants' negative versus positive explicit associations to puzzle pieces were negative, whereas only a third of their explicit associations to non-puzzle piece shapes were negative.

Although for some phenomena, people's explicit associations differ from their implicit associations (Nosek, 2005); the general public's negative explicit associations to puzzle pieces corroborate their negative implicit associations. Stronger corroboration between people's explicit and implicit associations indicates a more valid assessment of each type of association (Greenwald et al., 2009).

This study also demonstrated that the general public's negative bias against puzzle pieces applies to generic puzzle pieces, as well as to puzzle pieces used in autism logos. Our participants' explicit associations inform us as to why. Participants associated puzzle pieces with imperfection, incompletion, uncertainty, difficulty, the state of being 
unsolved, and, most poignantly, being missing. Some of the participants' explicit associations even referenced negative aspects of puzzle pieces' physical shape with associations such as odd shaped, jagged, and uneven.

Apart from the Wikipedia logo, the puzzle-piece imagery used in non-autism logos usually differs from the puzzle-piece imagery used in autism logos (see https://osf.io/mv2zt/ for the most frequent results of a Google image search).

Puzzle-piece imagery used in non-autism logos usually comprises interlocking, completed, and integral puzzle pieces; in contrast, puzzle-piece imagery used in autism-related logos usually comprises single puzzle pieces in isolation or incomplete puzzles with a piece missing, reifying our participants' associations of puzzles pieces as reflecting incompletion, imperfection, and the state of being unsolved.

This study's results not only support many autistic persons' claims about puzzle piece imagery but also bear public policy implications. If an autism organization's intention for using puzzle-piece imagery is to evoke negative associations, then the use of puzzle-piece imagery is apt. If, instead, an autism organization's intention for using puzzle-piece imagery is, as Grinker and Mandell (2015) report, "not meant to devalue" autistic persons "but, quite the opposite, to celebrate them," (p. 644) our results suggest that puzzle-piece imagery should probably be avoided.

\section{Availability of data and materials}

The data set and stimuli supporting the conclusions of this article are available in the Open Science Framework repository, https://osf.io/mv2zt/.

\section{Ethical approval and consent to participate}

Participants provided informed consent, and the experiment was approved by the Institutional Review Board at the University of Wisconsin-Madison (protocol SE-2013-0965).

\section{Declaration of conflicting interests}

The author(s) declared no potential conflicts of interest with respect to the research, authorship, and/or publication of this article.

\section{Funding}

The author(s) received no financial support for the research, authorship, and/or publication of this article.

\section{Note}

1. As Lakens (2013) notes, for matched-pair $t$-tests, the $t$-value and degrees of freedom provide the appropriate estimate of effect size.

\section{References}

Acosta MT and Pearl PL (2003) The neurobiology of autism: new pieces of the puzzle. Current Neurology and Neuroscience Reports 3: 149-156.
Brook K (2016) A response to 'notes on a puzzle piece.' Autism 20: 251-252.

CNRS (2015) Missing piece surfaces in the puzzle of autism. ScienceDaily. Available at: https://www.sciencedaily.com/releases/ 2015/08/150804074037.htm

Crawford C (2004) Solving the autism spectrum puzzle. Alaska Special Education Service Area Newsletter 62(2): 2-4.

Devos T and Ma DS (2008) Is Kate Winslet more American than Lucy Liu? The impact of construal processes on the implicit ascription of a national identity. British Journal of Social Psychology 47: 191-215.

Edmunds DL (2013) A puzzle piece? The need for a new symbol for autistics. Psychology Today. Available at: https:// www.psychologytoday.com/blog/extreme-states-mind/201305/puzzlepiece-the-need-new-symbol-autistics

Endow J (2014) Goodnight autism puzzle pieces. Ollibean. Available at: http://ollibean.com/goodnight-autism-puzzle-pieces/

Foroni F and Bel-Bahar T (2010) Picture-IAT versus WordIAT: level of stimulus representation influences on the IAT. European Journal of Social Psychology 40: 321-337.

Goin-Kochel RP (2016) Musings on the puzzle piece. Autism 20: 250.

Greenwald AG, McGhee DE and Schwartz JLK (1998) Measuring individual differences in implicit cognition: the Implicit Association Test. Journal of Personality and Social Psychology 74: 1464-1480.

Greenwald AG, Nosek BA and Banaji MR (2003) Understanding and using the Implicit Association Test, I: an improved scoring algorithm. Journal of Personality and Social Psychology 85: 197-216.

Greenwald AG, Poehlman TA, Uhlmann EL, et al. (2009) Understanding and using the Implicit Association Test, III: meta-analysis of predictive validity. Journal of Personality and Social Psychology 97: 17-41.

Grinker RR and Mandell D (2015) Notes on a puzzle piece. Autism 19: 643-645.

Healy EM (2008) Improving autism policies beyond the enigma: current challenges and future considerations for improving policies to support individuals living with autism. Speaker's Journal 8: 141-156.

Heilker P and Yergeau M (2011) Autism and rhetoric. College English 73: 485-497.

Hillary A (2013) Red flags. Yes, That Too. Available at: http:// yesthattoo.blogspot.com/2013/01/red-flags.html

Ised E (2012) Puzzling people. The Standard Review. Available at: http://diversityrules.typepad.com/my_weblog/2012/04/puzzlingpeople.html

Koll O, von Wallpach S and Kreuzer M (2010) Multi-method research on consumer-brand associations: comparing free associations, storytelling, and collages. Psychology \& Marketing 27: 584-602.

Krishnan HS (1996) Characteristics of memory associations: a consumer-based brand equity perspective. International Journal of Research in Marketing 13: 389-405.

Lakens D (2013) Calculating and reporting effect sizes to facilitate cumulative science: a practical primer for. Frontiers in Psychology 4: 863.

McGuire AE (2012) On the "puzzle of autism" and the incompleteness of autism awareness. Journal on Developmental Disabilities 18: 96-100. 
McGuire AE and Michalko R (2011) Minds between us: autism, mindblindness and the uncertainty of communication. Educational Philosophy and Theory 43: 162-177.

Maison D, Greenwald AG and Bruin RH (2004) Predictive validity of the Implicit Association Test in studies of brands, consumer attitudes, and behavior. Journal of Consumer Psychology 14: 405-415.

Muzikar D (2015) The autism puzzle piece: a symbol that's going to stay or go? The Art of Autism. Available at: http://the-artof-autism.com/the-autism-puzzle-piece-a-symbol-of-what/

Nakhla-Thometz A (2013) Today on "what really grinds my gears": a puzzle piece as a symbol for autism. Angry Autie. Available at: https://angryautie.wordpress.com/2013/06/14/todayon-what-really-grinds-my-gears-a-puzzle-piece-as-a-symbol-forautism/

National Autistic Society (2007) Perspectives on a puzzle piece. Available at: http://web.archive.org/web/20070714093137/http:/ www.nas.org.uk/nas/jsp/polopoly.jsp?d=364\&a=2183

Nosek BA (2005) Moderators of the relationship between implicit and explicit evaluation. Journal of Experimental Psychology: General 134: 565-584.

Nowicki EA, Brown J and Stepien M (2014) Children's structured conceptualizations of their beliefs on the causes of learning difficulties. Journal of Mixed Methods Research 8: 69-82.

O'Connor J (2009) Finding the missing puzzle piece of autism. New Science 17: 14.
Regan R (2015) Why the puzzle piece is an offensive symbol. Social Skills for Autonomous People. Available at: http:// realsocialskills.org/post/115578535827/why-the-puzzlepiece-isan-offensive-symbol

Sarrett JC (2011) Trapped children: popular images of children with autism in the 1960s and 2000s. Journal of Medical Humanities 32: 141-153.

Schaaf CP and Zoghbi HY (2011) Solving the autism puzzle a few pieces at a time. Neuron 70: 806-808.

Smukler D (2005) Unauthorized minds: how "theory of mind" theory misrepresents autism. Mental Retardation 43: $11-24$.

Spears N, Brown TJ and Dacin PA (2006) Assessing the corporate brand: the unique corporate association valence (UCAV) approach. Journal of Brand Management 14: 5-19.

State MW (2010) Another piece of the autism puzzle. Nature Genetics 42: 478-479.

Stevenson JL, Harp B and Gernsbacher MA (2011) Infantilizing autism. Disability Studies Quarterly 31(3): 1675.

Tucker T (2008) Post-puzzle piece autism. I Am An Autism Parent. Available at: http://iamanautismparent.com/post-puzzlepiece-autism/

Van Rijn H and Stappers PJ (2008) The puzzling life of autistic toddlers: design guidelines from the LINKX project. Advances in Human-Computer Interaction 2008: 639435.

Wyatt CS (2008) Logos, symbols, ribbons ... The Autistic Me. Available at: http://theautisticme.blogspot.com.au/2008/04/logossymbols-ribbons.html 